\title{
Investigation of Manhole Effects on the Seismic Response of Self-Supported Steel Chimneys
}

\author{
A.Mehrazad TahamouliRoudsari, B.Ehsan Khosravi, C. Mohamad Amin Sharafiani
}

\begin{abstract}
Industrial steel chimneys are one of the most important shell shaped structures which are located at the power plants and petrochemical factories. The collapses of these structures during destructive earthquakes result in delay of industrial productions. Existence of manhole at the bottom of chimneys provide inspection purposes and access to inner part of the structure. It is so clear that existence of manhole decline strength and stiffness of the structure. Therefore, presence of series of stiffeners compensate weakness in this structures. In the first part of this paper sensitivity analyses were done on the structure for calculating the most economical design of steel chimney during impressive earthquakes. At the second part pushover analyses were done on the structure for chimney with manhole, without manhole and with consideration of stiffeners. At the third part nonlinear dynamic analyses applied on the structure for achieving exact response of structure. Finally the capacity curves obtained from different analyses, and then these curves compared together.
\end{abstract}

Index Terms - steel chimney, manhole, stiffener, IDA and pushover analysis

\section{INTRODUCTION}

Industrial self-supported steel chimneys are in the group of cylindrical and high-rise structures. The performance of these special structures during earthquakes could be important and problematic issue. Therefore, these structures must be in safe position during any kind of earthquakes.

In the last decade chimneys were considerated by some of researchers, and this section refers to some these studies. Tadeusz Chmielewski et al. (2005) studied about theoretical and experimental free vibrations of tall chimney By considering soil structure interaction. In this study vibration frequencies and natural mode shapes of the tall chimney with height of 250 meters have been calculated by using the finite element method. Experimental investigations of the free vibration response have been done by using two geophone sensors.

Finally the numerical and experimental results have been verified [1]. lemak, and Studnicka, (2005) explained about the effects of ring-shaped stiffeners on steel chimneys for rehabilitation of these structures, and relationships are indicated for stresses in stiffeners [2].

F. A. Assistant Professor, Department of Civil Engineering, Kermanshah Branch, Islamic Azad University, Kermanshah, Iran.

S. B. M. Sc. In Civil Eng., Department of Civil Engineering, Kermanshah Branch, Islamic Azad University, Kermanshah, Iran.
Francisco et al. (2006) review the seismic behavior of masonry chimneys. This paper engages in the seismic response of an unreinforced masonry chimney that is common in many European countries. A finite element model compatible of reproducing fracturing and crushing phenomena carried out in an inelastic analysis in order to achieve displacements, failure pattern and collapse mode for these chimneys [3]. Bajpai et al.(2007) presented the vibration-dampers for steel chimneys. In this paper, principle of the damping system is mentioned. Two important parameters like stiffness and mass of the damper are evaluated [4].

Simonović et al. (2008) carried out stress and force distribution as a cause of chimneys root section failure. This paper has studied failure of the root section steel chimneys with height of 60 meters [5]. Nikhil and Unnikrshnan. (2008) presented optimization of a steel chimney. In this paper a steel chimney was considerated by dealing with dead, wind and thermal load. Processes were done for the design of the structures. The chimney was modeled by using ANSYS software [6].

At the first part of this paper a great number of different earthquakes with consideration of various characteristics of earthquakes (peak ground acceleration, duration and frequency content) were applied on the structure. Each record of earthquakes with consideration of three different component were applied on structure simultaneously, and then time history analysis were done. The results show that CHICHI TAIWAN 1994 earthquake cause inelastic phases on bottom of the chimney. Therefore, this earthquake selected as a basic record for sensitivity analysis, and then variable thicknesses used at the base of the chimney for calculating economical thickness.

The reduction of sectional area decreases stiffness and strength of structures. Manholes are one of the inevitable and unavoidable parts of chimneys. These weaknesses must be compensating by adding set of stiffeners at the bottom of chimney. at the second part pushover analysis applied on the chimney with manhole, without manhole and with consideration of stiffeners, and then suitable dimension of stiffeners for compensating the weakness that it caused by existence of manhole were selected. At the third part for achieving to exact response of structure, incremental dynamic analyses (IDA) were applied on the structure without manhole, with manhole and with consideration of stiffeners. 


\section{II. the characteristics of steel chimney}

The characteristics of steel chimney show in Fig. 1. This chimney is made up of circular section with constant thickness. The thickness of the chimney equals to 11 millimeters.

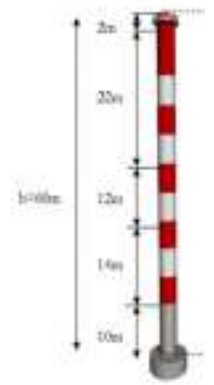

Fig. 1. Details of the steel chimney [7].

\section{III. properties of materials}

Steel CORTEN S355 is the material that utilized in this study. TABLE I indicates mechanical properties of steel CORTEN S355. This kind of steel is usual materials that are used for industrial steel chimneys.

TABLE I: MECHANICAL PROPERTIES OF STEEL CORTEN S355 [7]

\begin{tabular}{||c|c|c|c||}
\hline \hline Mechanical Properties & Symbol & Price & Measurment Units \\
\hline Elasticity Module & $\mathrm{E}$ & 199.00 & $\mathrm{GPA}$ \\
\hline Poisson Ratio & $v$ & 0.33 & - \\
\hline Density & $\rho$ & 7850.0 & $\mathrm{Kg} / \mathrm{m} 3$ \\
\hline Yield in capacity & $\mathrm{f}_{\mathrm{y}}$ & 355.00 & $\mathrm{MPa}$ \\
\hline Ultimate capacity & $\mathrm{f}_{\mathrm{u}}$ & 470 & $\mathrm{MPa}$ \\
\hline
\end{tabular}

\section{Numerical Modeling verification}

To verify the numerical modeling of chimney, the period obtained from both the equation proposed by ASCE7 code [8] and the finite element method software were compared. For achieving to this purpose, steel chimney with constant thickness of $10 \mathrm{~mm}$ was modeled. In the next step the period of chimney was calculated by using of the equations that suggested in AISC guide line. Then he period of structure was computed by using the finite element software ABAQUS. Geometric characteristic and material of steel chimney indicate in Fig. 2 and TABLE II, respectively. The equations 1 and 2 represent moment of inertia and period of structure.

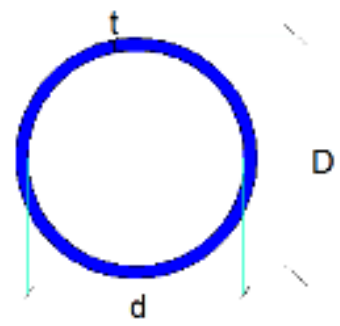

Fig. 2. Geometry of section of steel chimney.

$$
\mathrm{I}=\pi \mathrm{r}^{4} / 4
$$

$$
\mathrm{T}=0.018 \mathrm{~L}^{2} \sqrt{ }(\mathrm{q} / \mathrm{g} \text { E I })
$$

TABLE II: FEATURES OF CHIMNEY

\begin{tabular}{||c|c|c|c|c|c|c|}
\hline $\begin{array}{c}\mathrm{L} \\
\mathrm{m}\end{array}$ & $\begin{array}{c}\mathrm{D} \\
\mathrm{m}\end{array}$ & $\begin{array}{c}\mathrm{d} \\
\mathrm{m}\end{array}$ & $\begin{array}{c}\mathrm{t} \\
\mathrm{m}\end{array}$ & $\begin{array}{c}\mathrm{q} \\
\mathrm{Kg} / \mathrm{m}\end{array}$ & $\begin{array}{c}\mathrm{E} \\
\mathrm{Kg} / \mathrm{cm}^{2}\end{array}$ & $\begin{array}{c}\mathrm{I} \\
\mathrm{m}^{4}\end{array}$ \\
\hline 50 & 2 & 1.98 & 0.01 & 490.76 & $2.1 \mathrm{E} 6$ & 0.03095 \\
\hline
\end{tabular}
L: Hight of the chimney
D: Outer diameter
d: Inner diameter
t: Thickness
q: Weight per unit length
E: Modulus of elasticity
I: Moment of inertia

TABLE III presents differences between periods were obtained from both the finite element method and the proposed equations. The results show a very small difference between the two methods.

TABLE III: FEATURES OF CHIMNEY

\begin{tabular}{||c|c|c|c||}
\hline $\begin{array}{c}\mathrm{L} \\
(\mathrm{m})\end{array}$ & $\begin{array}{c}\text { ASCE7 T } \\
(\mathrm{sec})\end{array}$ & $\begin{array}{c}\mathrm{T} \\
\text { FEM(sec) }\end{array}$ & $\begin{array}{c}\text { ERROR } \\
\%\end{array}$ \\
\hline 50 & 1.248 & 1.261 & 1 \\
\hline
\end{tabular}

\section{V. sensitivity analyses for steel chimney}

Having enough knowledge about the performance of chimney during different earthquakes lead to exact, economic and reliable design of these structures, so in this part an economic design of chimney is noticeable. At first step, 10 different earthquakes based on TABLE IV applied on the chimney with consideration of three components of records simultaneously, and then time history analyses performed on structures. Results show only CHICHI TAIWAN 1994 earthquake caused structured in inelastic phases and this phenomenon occurred at bottom part of the structure. The height of this region which is yielded approximately equals to 9 meters based on Fig. 3.

For reinforcing the chimney, a rejoin with variable height (h) that begin from surface level of the foundation up to $h$ level strengthened by adding the thickness. Fig. 3 shows yielded region of the structure. At the firs try, the height of reinforced rejoin selected as 10 meters because the height of yielded rejoin was 9 meters. Thickness of reinforced rejoin increased gradually in $12,13,14,15,20,25,30,35$ and 40 millimeters. Results show for reinforced rejoin by thickness of 40 millimeters inelastic phases occurred at the bottom of structure.

In the next step height of reinforced rejoin selected as 15 and 20 meters and for different thicknesses (thicknesses equal to $12,13,14,15,20,25$, and 30). Finally the height of reinforced rejoin were obtained, and this height equaled to $H / 3$ ( $\mathrm{H}=$ height of chimney). 


\section{Nonlinear static analysis (PUSHOVER)}

Nonlinear static analysis (pushover) has been used since 1970, and has been made remarkable progress in the last 20 years. Using this method is recommended by most codes to evaluate the seismic performance of structures. In this method, after applying the gravity loads, structures subjected to lateral loads with a specific pattern that it gradually increases. Therefore, at each step the lateral displacement gradually increases. Pushover analysis is a simple method for evaluating the performance of structures that it provides the capacity curve, the yielding and failure points of the structures.

TABLE IV: CHARACTERISTIC OF EARTHQUAKES

\begin{tabular}{|c|c|c|c|c|}
\hline earthquakes & $\begin{array}{c}\text { magnitude } \\
\text { (righter) }\end{array}$ & $\begin{array}{c}\text { PGA } \\
\text { N_S }\end{array}$ & $\begin{array}{c}\text { PGA } \\
\text { E-W }\end{array}$ & $\begin{array}{c}\text { PGA } \\
\text { Vertical }\end{array}$ \\
\hline CHICHI TAIWAN 1999 & 7.6 & 0.968 & 0.902 & 0.724 \\
\hline NORTHRIDGE 1994 & 6.7 & 1.585 & 1.285 & 1.229 \\
\hline NAHANNI CANADA 1985 & 6.9 & 2.086 & 1.096 & 0.978 \\
\hline SANFERNANDO 1971 & 6.6 & 1.226 & 1.16 & 0.699 \\
\hline GAZII 1976 & 20 & 1.267 & 0.608 & 0.718 \\
\hline MOMMOTH LAKES 1980 & - & 0.271 & 0.43 & 0.271 \\
\hline CAPE MENDOCION 1992 & 7.1 & 1.497 & 1.039 & 0.754 \\
\hline IMPERIALVALLEY 1979 & 6.5 & 1.655 & 0.439 & 0.41 \\
\hline TABAS IRAN 1978 & 7.4 & 0.836 & 0.852 & 0.688 \\
\hline MORGAN HILL 1984 & 1 & 1.298 & 0.711 & 0.388 \\
\hline
\end{tabular}

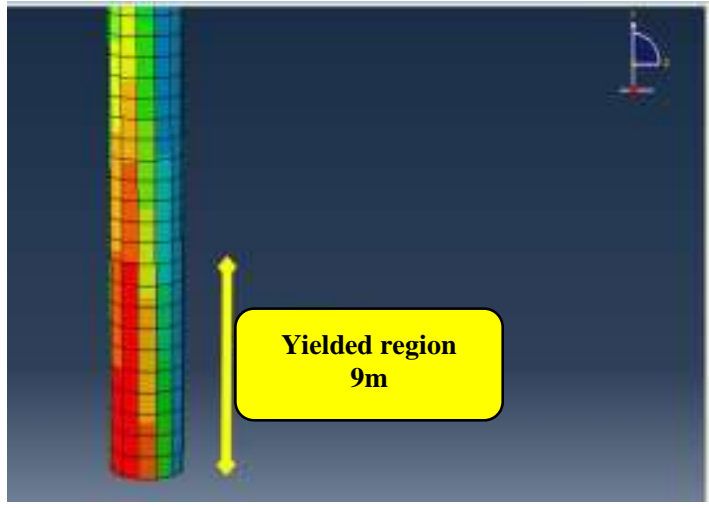

Fig. 3. Height of yielded region

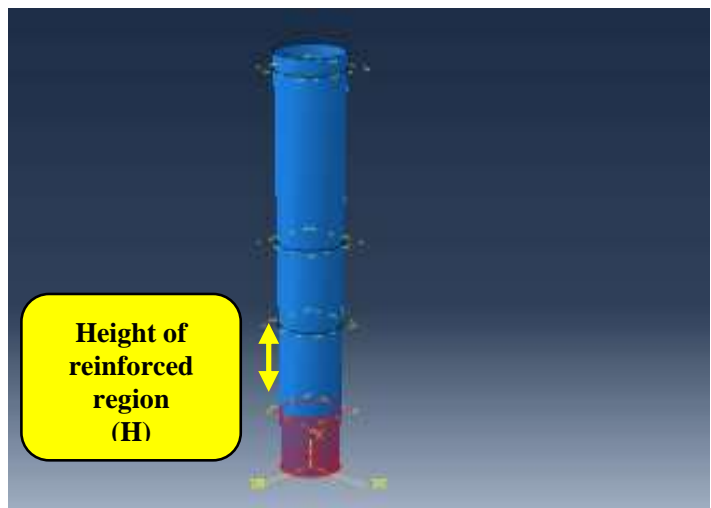

Fig. 4. Height of reinforced region
This analysis was performed for chimneys. For this purpose, the modal analyses were performed on the structure and mode shapes of the structure were obtained. This deformation was applied as a lateral displacement pattern on the structure, and the structure were analyzed by pushover method. Lateral displacement was applied until it reaches to $0.05^{*} \mathrm{H}$ ( $\mathrm{H}$ is height of structure). Fig. 5 shows the result for pushover analysis of structure.

It is so clear that existence of manhole on the chimney for access and observation inner part of this structure decline seismic performance, and it reduce initial stiffness and strength of this structure. For investigating manhole effects, two rectangular manhole with standard dimension that is suggested by IS code [9] are used. Fig. 6 shows standard characteristics of manholes which is recommended by IS code. These two manholes located at the bottom of the chimney and they are in a symmetric position.

For observing effects of manholes, pushover analysis was performed on the structure. The capacity curve (displacement vs base shear) for this chimney was plotted. Fig. 7 demonstrates capacity curves for chimney without manholes and with consideration of manholes. The results show that the capacity curve of chimney with manholes has changed significantly. All inevitable parameters like initial stiffness, yielding strength, ultimate strength, and energy dissipation of structure decreased with existence of manholes.

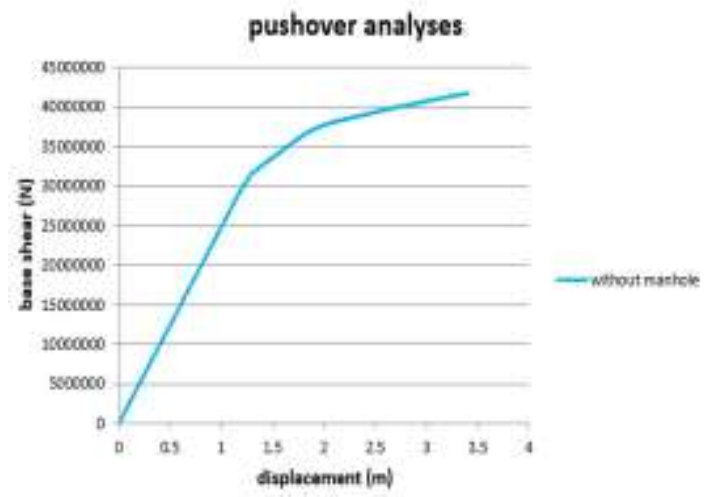

Fig. 5. Capacity curve obtained from pushover analysis
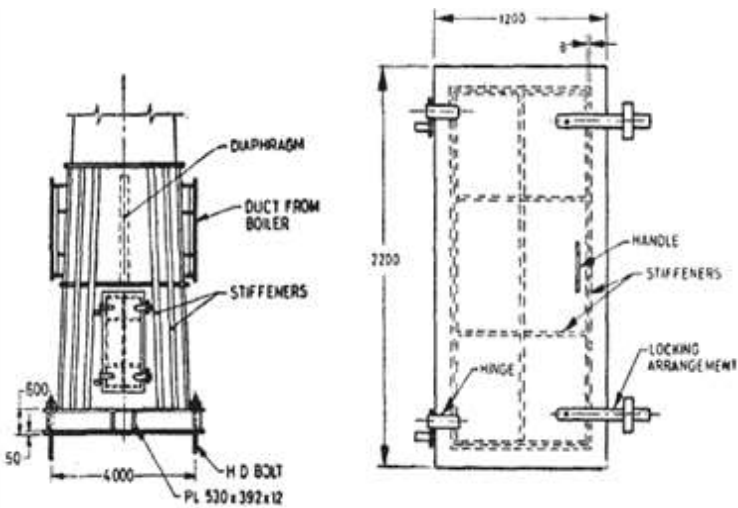

Fig. 6. Details of manhole suggested by the IS code [9] 


\section{VII. suggestion of appropriate stiffeners}

Based on section VI, existence of manholes reduce important parameters in capacity curve (initial stiffness, yielding strength, ultimate strength and energy dissipation of structure). These weaknesses must be compensated by added special stiffeners. One of most usual, and efficient stiffeners are triangular bending stiffeners which are located at the bottom of chimney. Therefore, existence of triangular bending stiffeners could improve performance of the structure. Fig. 8 shows the characteristic of triangular bending stiffeners.

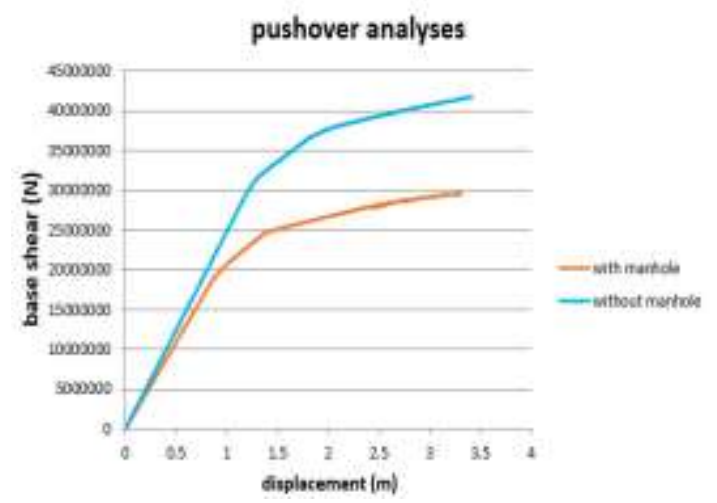

Fig. 7. Capacity curves for chimney without manholes and with consideration of manholes

In this section the dimensions for triangular bending stiffeners were obtained by sensitivity analyses. For this model width of stiffeners calculated as $1.5 \mathrm{~m}$, height of stiffeners as $5 \mathrm{~m}$ and thickness of stiffeners as $0.03 \mathrm{~m}$. Fig. 9 demonstrate the capacity curves of chimney for finding the best dimensions of stiffeners which are obtained by nonlinear sensitivity analyses. According to Fig. 9, stiffeners with height of 5 meters, width of $1.5 \mathrm{~m}$ and variable thickness were used in pushover analyses. Pushover analyses performed for steel chimney with manhole and stiffeners with variable thicknesses like 0.03, 0,025, 0.020, 0.015 meter. From Fig. 9, it can be concluded that stiffeners with 5 meter height, 1.5 meter width and 0.03 meter thickness are appropriate

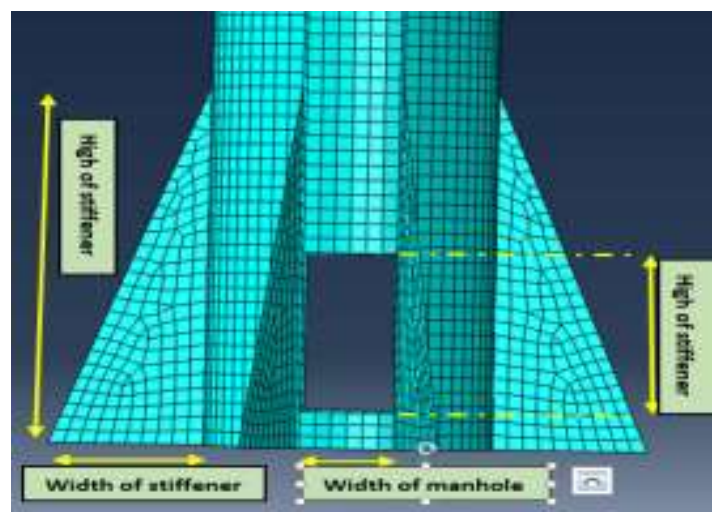

Fig. 8. Characteristic of triangular bending stiffeners

Fig. 10 illustrated capacity curves of chimney without manholes, with manhole and with consideration of both manholes and stiffeners which are obtained by pushover analyses. It is obvious that existence of stiffeners improve performance of the chimney.

\section{VIII. incremental nonlinear dynamic analysis (IDA)}

Incremental nonlinear dynamics analyses (IDA) is one of the most important and complex types of time history analyses. Although static analyses are conservative and simple, nonlinear analyses can calculate exact and reasonable behavior of structures. Incremental nonlinear dynamics analyses (IDA) contain a great number of nonlinear dynamic analyses under different earthquake records. These records were scaled in a way that these can cover linear and nonlinear range of behavior of structure. The main target of this method is to calculate response of structure with various values of earthquake intensity. The results of these analyses are presented as IDA curves. In this part, records of earthquakes are normalized in Peak Ground Acceleration (PGA). Consequently, these values multiply in different coefficient of gravity $(0.1 \mathrm{~g}, 0.2 \mathrm{~g}, 0.3 \mathrm{~g} \ldots)$. Then, structures were analyzed under different values of PGA.

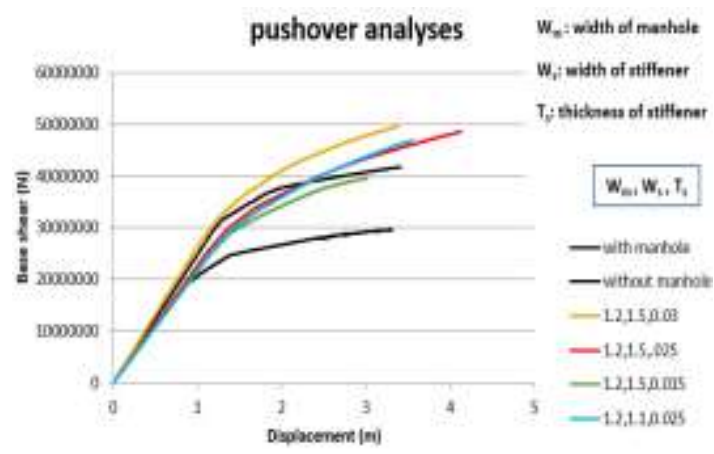

Fig. 9. Pushover analyses with different size of stiffeners

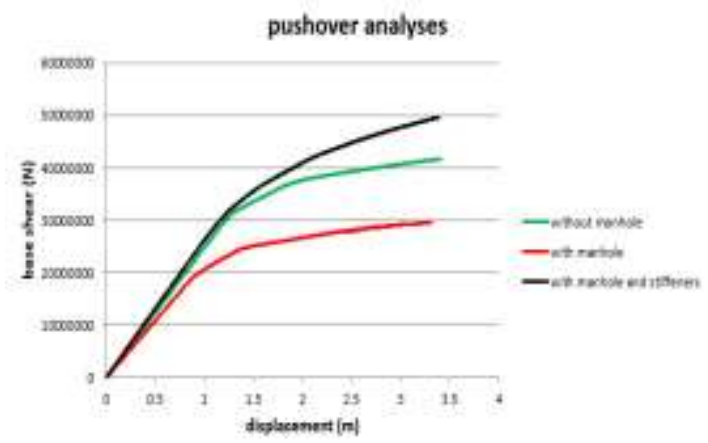

Fig. 10. Pushover analyses for chimney without manhole, with manhole and with consideration of manhole and stiffeners

Finally, the responses of structure (displacement and base shear) versus PGA were plotted. In this study non-linear dynamic analysis (IDA) for CHICHI TAIWAN 1999 and NORTHRIDGE 1994 earthquake were done. For both earthquakes, capacity curves were obtained (for this purpose more than 100 analysis were carried out). This procedure was applied for chimneys with and without existence of manhole. Therefore, base shear versus displacement curve plotted. Capacity curve obtained from Incremental nonlinear dynamics analyses for CHICHI TAIWAN 1999 and NORTHRIDGE 1994 earthquakes that represent respectively in Fig. 11, 12. Fig. 13 shows capacity curves that obtained from pushover analysis and IDA with and without manholes. 
Fig. 13 shows that pushover curve has good agreement with response of structure. TABLE V compares initial stiffness and energy dissipation of steel chimney with and without manhole for IDA and pushover analyses. It is so clear that existence of manhole changes response of structure under the earthquakes (decline in initial stiffness, energy dissipation and ultimate strength).Using of stiffeners in steel chimneys with consideration of manhole result in rehabilitation of response of structures. In next part, the effect of stiffeners on the chimney's initial stiffness and energy dissipation are considered.

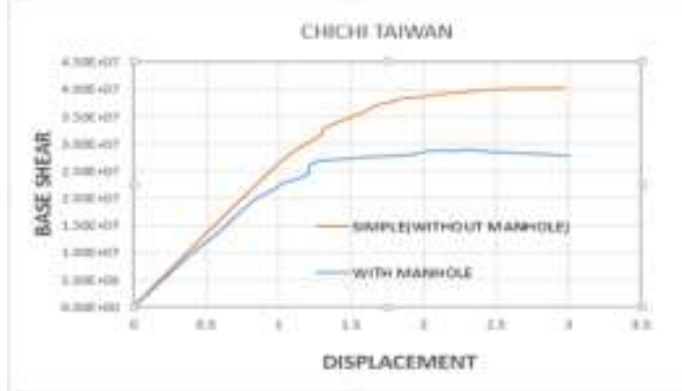

Fig. 11. Capacity curve obtained from IDA (CHICHI TAIWAN 1999)

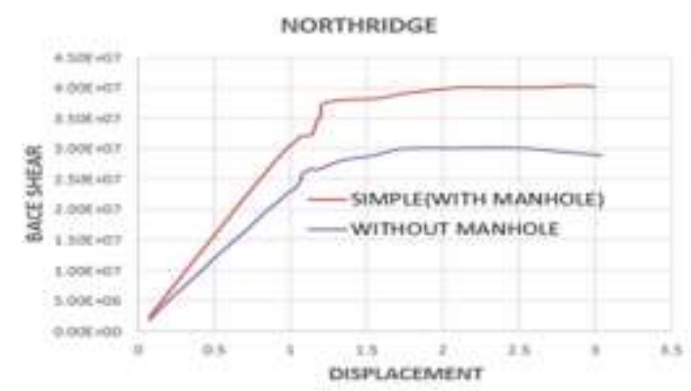

Fig. 12. Capacity curve obtained from IDA (NORTHRIDGE 1994)

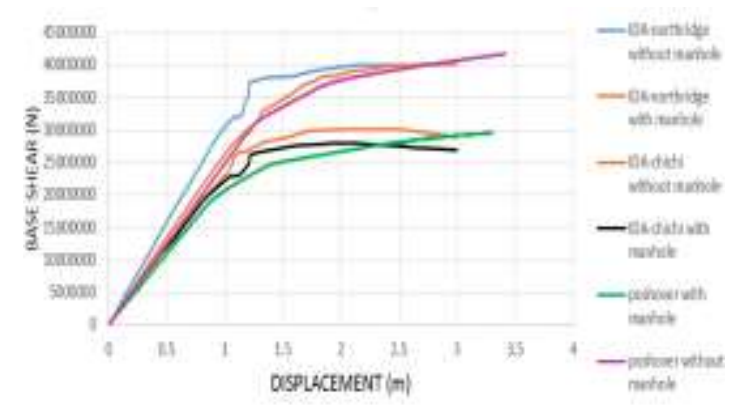

Fig. 13. Comparison of IDA and pushover (with and without manhole)

TABLE V: COMPARISON INITIAL STIFFNESS AND ENERGY DISSIPATED OF STEEL CHIMNEY WITH AND WITHOUT OPENING

\begin{tabular}{|l|c|c|}
\hline & $\begin{array}{c}\text { Stiffness } \\
(\mathbf{N} / \mathbf{m})\end{array}$ & $\begin{array}{c}\text { Dissipated energy } \\
(\mathbf{N} . m)\end{array}$ \\
\hline pushover- without manhole & $3.31 \mathrm{E}+07$ & $1.07 \mathrm{E}+08$ \\
\hline pushover- with manhole & $2.25 \mathrm{E}+07$ & $6.25 \mathrm{E}+07$ \\
\hline IDA-(Chichi)-without manhole & $2.68 \mathrm{E}+07$ & $8.55 \mathrm{E}+07$ \\
\hline IDA-(Chichi)-with manhole & $2.43 \mathrm{E}+07$ & $6.58 \mathrm{E}+07$ \\
\hline IDA-(Northridge)-without manhole & $3.15 \mathrm{E}+07$ & $9.28 \mathrm{E}+07$ \\
\hline IDA-(Northridge)-with manhole & $2.57 \mathrm{E}+07$ & $7.00 \mathrm{E}+07$ \\
\hline
\end{tabular}

\section{Incremental Nonlinear dynamic and pushover analyses of steel chimney with manhole and stiffeners}

Fig. 14 shows the IDA analyses of TAIWAN CHICHI earthquake. At first step, capacity curve with manhole was plotted. At next step, capacity curve with manhole and stiffener with 5 meter height, 1.5 meter width and 0.025 thickness were plotted. Dissipation energy with existence of stiffeners increases $18.33 \%$ and yielding force $21.66 \%$ that indicate positive performance of stiffeners.

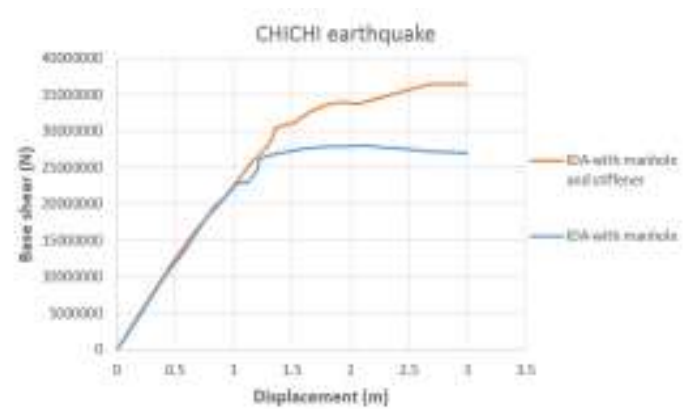

Fig. 14. Capacity curves obtained from IDA analyses (CHICHI earthquake)

\section{X. conclusion}

At the first part of this paper 10 different earthquakes were applied on the structure and time history analyses were conducted. CHCHI TAIWAN 1994 earthquake cause inelastic phases at the bottom of chimney, by using of sensitivity analyses the economical design for the structure suggested by using nonlinear time history analyses. At the second part different types of analyses performed on the self-supported steel chimney with consideration of manhole and triangular stiffeners. Results show existence of manholes at the bottom of chimney decline significantly initial stiffness, strength and energy dissipation, therefore for compensating these weaknesses special triangular stiffeners were added on the structure. Pushover and IDA analyses were performed, and capacity curve of structure with manhole, without manhole and with consideration of triangular bending stiffeners were obtained. Finally the most economic dimension of triangular stiffeners for compensating the weaknesses of chimney suggested.

\section{REFERENCES}

[1] Tadeusz Chmielewski, Piotr Górski, Bernd Beirowb, Joachim Kretzschmar,"Theoretical and experimental free vibrations of tall industrial chimney with flexibility of soil," Engineering Structures 27 25-34, Elsevier,2005

[2] D-lemak,j.studnicka, "behavior of steel cylindrical shells," proceedings international conference VSU.32 45-34, 2004.

[3] Francisco J. Pallare's, Antonio Agu"ero, Manuel Martı'n, "Seismic behaviour of industrial masonry chimneys," International Journal of Solids and Structures 43 - 2076-2090, Elsevier, 2006.

[4] V K BAJPAI, T K GARG, MANOJ KUMAR GUPTA, "Vibration-Dampers for Smoke Stacks," 3rd WSEAS International Conference on APPLIED and THEORETICAL MECHANICS, Spain, December 14-16,2007. 


\section{Proc. of The Fourth Intl. Conf. On Advances in Civil and Structural Engineering - CSE 2015}

Copyright (C) Institute of Research Engineers and Doctors, USA .All rights reserved.

ISBN: 978-1-63248-070-5 doi: 10.15224/ 978-1-63248-070-5-42

[5] Simonović, Aleksandar M., Slobodan N. Stupar, and Ognjen M. Peković. "Stress distribution as a cause of industrial steel chimney root section failure," FME Transactions 36.3 119-125, 2008.

[6] Nikhil Asok, N., and M. Unnikrshnan, "Design and optimization of a steel chimney," 2010.

[7] C. Gantes, Associate Professor., "Behaviour, Analysis and Design of Steel Chimneys," national technical university of athens department of civil engineering atluri, , tech science press, usa, 2011.

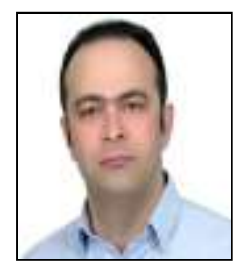

First A. Author DR. Mehrazad TahamouliRodsari was born in Roudsar, Iran, in 1973. He graduated in civil engineering doctoral in Lifeline Earthquake Engineering branch from the University of Science and Research of Tehran in 2011. He is an assistant professor of civil engineering and director of the Department of Civil Engineering of the Islamic AZAD University of Kermanshah. With numerous articles, including:

TahamouliRoudsari, Mehrzad and Hosseini, Mahmood, On the Relation Between Rigorous and Simplified Models for the Dynamic Response Analysis of Multicomponent and Multisupport Excitations, Journal of Earthquake Spectra, Volume 29, No. 2, pp. 527-546, 2013.

Hosseini, Mahmood and TahamouliRoudsari, Mehrzad, Minimum Effective Length and Modified Criteria for Damage Evaluation of Continuous Buried Straight Steel Pipelines Subjected to Seismic Waves, Journal of Pipeline Systems Engineering and Practice, ASCE, DOI: http://dx.doi.org/10.1061/(ASCE)PS.1949-1204.0000193, 2014.

TahamouliRoudsari, Mehrzad, F. Abdollahi, H. Salimi, S. Azizi and A.R. Khosravi, The Effect of Stiffener on Behavior of Reduced Beam Section Connections in Steel Moment-Resisting Frames, International Journal of Steel Structures, Springer, 2015 (Accepted and Under Publication).

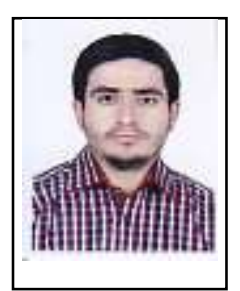

Second B. Author Ehsan Khosravi was born in kamyaran, Iran, in 1989. He graduated in civil engineering master of science in Earthquake Engineering brench from the University of Science and Research of kermanshah in 2014. With numerous articles, including:

Seven Persian national and international articles about steel chimneys and steel plate shear walls

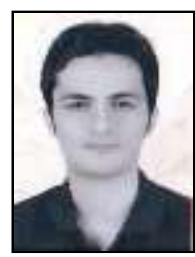

Third C. Author Mohamad Amin Sharafiani was born in kermanshah, Iran, in 1991. He graduated in civil engineering master of science in Earthquake Engineering brench from the University of Science and Research of kermanshah in 2014. With numerous articles, including: Seven Persian national and international articles about steel chimneys and steel plate shear walls.
[8] ASCE. "Minimum Design Loads for Buildings and Other Structures." ASCE 7-98, Reston, Va, 1999.

[9] IS 6533 Part 2; 1989, "Design and Construction of Steel Chimney", Bureau of Indian Standards, New Delhi 2005. 